\title{
ПРОИЗВОДСТВО ФУНКЦИОНАЛЬНЫХ ЯИЦ. Сообщение III. РОЛЬ КАРОТИНОИДОВ

\author{
(обзор)
}

\section{А.Ш. КАВТАРАШВИЛИ, И.Л. СТЕФАНОВА, В.С. СВИТКИН}

Изучение роли каротиноидов, особенно ксантофиллов, в профилактике и диетотерапии ряда онкологических, сердечно-сосудистых и глазных болезней человека (Е. Bakan с соавт., 2014) привело к тому, что сейчас эти соединения стали рассматриваться не только как средство улучшения окраски и товарного вида желтка яиц, но и как целевые вещества при производстве диетических, дизайнерских и функциональных яиц (V.P. Singh с соавт., 2012). Высокая биодоступность каротиноидов из пищевых яиц (благодаря солюбилизации в липидах желтка) делает их удобным средством обогащения рациона человека (Н.-Y. Chung с соавт., 2004). В настоящем обзоре рассматриваются вопросы, связанные с практическим производством яиц, функциональных по каротиноидам: источники каротиноидов в рационах птицы и их сравнительная эффективность, метаболизм ксантофиллов в организме кур и его связь с метаболизмом липидов, влияние различных источников ксантофиллов на здоровье и продуктивность несушек, основные показатели качества яиц, интенсивность окрашивания желтка и содержание в нем ксантофиллов. Достоинство синтетических препаратов каротиноидов - их высокая усвояемость несушками (М. Marounek c соавт., 2016). При этом такие препараты из-за их стоимости не всегда целесообразно применять для производства обогащенных яиц. Натуральные источники основных ксантофиллов желтка, лютеина и зеаксантина (С.М. Вострикова с соавт., 2011), например цветки бархатцев (Tagetes spp.), содержат значительные количества эфиров ксантофиллов с жирными кислотами, которые усваиваются заметно хуже омыленных форм (К. Lokaewmanee с соавт., 2011). Такие источники можно подвергать предварительному омылению для высвобождения этерифицированных ксантофиллов, что повышает не только доступность ксантофиллов для несушек (на 40-60 \%), но и эффективность отложения этих соединений в желток (H. Hencken, 1992), но не сдвигает жирнокислотный профиль липидов желтка в сторону увеличения доли насыщенных жирных кислот (A. Altunta c coавт., 2014). К недостатком такого подхода относится низкая стабильность получаемых препаратов при хранении, поэтому рекомендуется их замораживать и как можно быстрее использовать после вскрытия заводской упаковки. Данные о влиянии разных источников ксантофиллов на продуктивность несушек (прежде всего, интенсивность яйценоскости и массу и морфологию яиц) неоднозначны: в ряде исследований отмечено достоверное улучшение таких показателей, тогда как в других опытах они не отличались от контроля или несколько снижались. Большинство исследованных источников (при условии доступности содержащихся в них ксантофиллов для несушек) значительно и достоверно улучшают показатели интенсивности окрашивания желтка (снижают индекс светлости $L^{*}$ при повышении индексов желтизны $b^{*}$ и красноты $\left.a^{*}\right)$, а также содержание в желтке лютеина и зеаксантина. При правильном подборе источников и доз концентрацию ксантофиллов в яйцах можно довести до значений, позволяющих считать такие яйца функциональными по каротиноидам (А. Sahoo с соавт., 2014), хотя потребление человеком ксантофиллов, безотносительно к конкретным заболеваниям, в целом пока не нормировано (Е. Toti с соавт., 2018).

Ключевые слова: функциональные яйца, каротиноиды, лютеин, зеаксантин, рацион курнесушек, кормовые источники каротиноидов, качество желтка.

В предыдущих сообщениях мы рассматривали вопросы, связанные с производством куриных яиц, функциональных по жирным кислотам (1), селену, цинку и йоду (2), а также обогащение (биофортификацию) яиц витаминами и каротиноидами (3). В этой части серии наших обзоров специальное внимание уделено производству яиц, функциональных по каротиноидам, поскольку в настоящее время накапливаются сведения об этих веществах как средстве профилактики ряда заболеваний

* «Производство функциональных яиц. Сообщение І. Роль в журнале «Сельскохозяйственная биология», 2017, том 52, № 2: 349-366 (doi: 10.15389/agrobiology.2017.2.349rus, doi: 10.15389/agrobiology.2017.2.349eng). «Производство функциональных яиц. Сообщение II. Роль селена, цинка, йода (обзор)» см. в журнале «Сельскохозяйственная биология», 2017, том 52, № 4: 700-715 (doi: 10.15389/agrobiology.2017.4.700rus, doi: 10.15389/agrobiology.2017.4.700eng). Работа финансово поддержана РНФ, грант № 16-16-04047. 
человека.

По химической природе каротиноиды представляют собой тетратерпеновые пигменты с окраской, варьирующей от бледно-желтой до темно-красной (4), которые синтезируются многими микроорганизмами и растениями, а также некоторыми водорослями и грибами. Организм животных синтезировать каротиноиды de novo не способен (5). Известно уже более 750 этих соединений, и их список каждый год пополняется (6). Они могут образовывать эфиры с жирными кислотами и комплексы с сахарами и белками (7). Некоторые из них, например $\beta$ - и $\gamma$-каротины, криптоксантины, но далеко не все проявляют А-провитаминную активность (8). Известно около 50 каротиноидов с А-провитаминной активностью (9). Своей окраской каротиноиды обязаны цепочкам конъюгированных двойных связей, выступающим в качестве хромофорной группы (10). Эти же структуры ответственны за антиоксидантные свойства каротиноидов: чем больше в молекуле каротиноида сопряженных двойных связей, тем лучше выражена его способность связывать образующиеся активные формы кислорода или предотвращать их образование (11). Антиоксидантные свойства каротиноидов in vivo обусловлены их взаимодействиями с другими антиоксидантами, такими как витамины Е и С (12).

К важнейшим для человека каротиноидам, исходя из объема их потребления с различными продуктами и концентрации в плазме крови, относятся $\alpha$ - и $\beta$-каротины, ликопин (углеводородные каротиноиды, или каротины), лютеин, зеаксантин и $\beta$-криптоксантин (оксикаротиноиды, или ксантофиллы) (13). В общей сложности в рационе человека может присутствовать до 40 различных каротиноидов (14). Известно, что каротиноиды снижают риск возникновения некоторых видов злокачественных новообразований (рака груди, легких, яичников, простаты), сердечно-сосудистых заболеваний, болезней глаз (катаракта, возрастная дегенерация желтого пятна). Антираковая активность $\alpha$ - и $\beta$-каротинов, ликопина, кантаксантина и ряда других ксантофиллов связана с несколькими возможными механизмами. Каротиноиды с А-провитаминной активностью могут влиять на дифференциацию и деление раковых клеток; антиоксидантная активность защищает ДНК здоровых клеток от повреждения активными формами кислорода; иммуномодулирующий эффект усиливает контроль над канцерогенезом со стороны иммунной системы; усиление каротиноидами межклеточной сигнальной системы сдерживает экспансию инициированных раковых клеток (15). С антиоксидантной активностью каротиноидов связана и их роль в профилактике сердечно-сосудистых заболеваний: они защищают липопротеины низкой плотности от окисления, которое способствует развитию атеросклероза, в том числе коронарного (16). Связь между потреблением каротиноидов с пищей и частотой сердечно-сосудистых заболеваний была подтверждена масштабными обследованиями пациентов в Италии (17), Японии (18), странах Евросоюза (19), Коста-Рике (20).

Защитное действие при глазных болезнях проявляют прежде всего лютеин и зеаксантин - единственные каротиноиды, присутствующие в сетчатке и хрусталике глаза (21). Они входят в состав пигмента так называемого желтого пятна, или макулы (22). Для объяснения защитного эффекта каротиноидов против возрастной макулярной дегенерации было предложено два механизма. Первый обусловлен тем, что макулярный пигмент защищает фоторецепторы и эпителий сетчатки от особенно вредного для них голубого света, который хорошо поглощается как лютеином, так и зеаксантином (23). Второй механизм связан со снижением указанными каротиноидами оксидативного стресса, вызываемого светом и фотоинду- 
цированными изменениями метаболизма этой ткани (24). Антиоксидантным эффектом объясняют и снижение этими каротиноидами (особенно лютеином) частоты возникновения катаракты. Так, в опыте in vitro было показано, что лютеин может ингибировать индуцируемое ультрафиолетовым светом перекисное окисление липидов в культуре клеток эпителия сетчатки глаза человека (25).

Основной источник каротиноидов в рационе человека и животных - плоды и листья растений. Содержание в них каротиноидов и биологическая доступность этих вешеств зависят от вида растения, его зрелости, времени сбора урожая, условий выращивания и хранения (26). Биодоступность каротиноидов из концентрированных препаратов также может сильно варьировать (27). Например, из цельных сырых овощей в кишечнике всасывается порядка $5 \%$ каротиноидов, тогда как из мицеллярного раствора - до $50 \%$, поэтому физическая форма, в которой каротиноиды попадают к клеткам слизистой кишечника, чрезвычайно важна (28). Не меньшее значение имеет химическая форма каротиноидов. Известно, что у кур свободный лютеин всасывается намного эффективнее, чем его моноили диэтиловые эфиры, в виде которых этот каротиноид содержится, например, в цветках бархатцев, и что предварительный гидролиз этих эфиров повышает всасывание лютеина на 40-60\%. То же самое относится к эфирам зеаксантина и капсантина - каротиноида красного перца (29). Установлено, что в желток и другие ткани организма кур лютеин откладывается в основном в свободном виде $(80 \%)$ и в меньшей степени - в виде метаболитов, моно- и диэфиров и 3 '-оксолютеина (30). С другой стороны, следует отметить, что и моно-, и диэфиры каротиноидов также относятся к эффективным антиоксидантам, поскольку этерификация не затрагивает и не экранирует их полиизопреноидные цепи (31).

Поскольку большинство каротиноидов жирорастворимы, их всасывание и метаболизация связаны со всасыванием жиров. После всасывания в кишечнике и метаболизации в печени каротиноиды транспортируются в кровь липопротеинами низкой (неполярные каротиноиды, то есть каротины) либо высокой плотности (ксантофиллы, такие как лютеин или зеаксантин). Затем эти комплексы с липопротеинами разлагаются липопротеинлипазами с высвобождением свободных каротиноидов (32).

На эффективность всасывания каротиноидов влияет состав рациона. Так, в некоторых растениях кроме каротиноидов содержатся ингибиторы их всасывания (33). Сообщалось также, что всасывание каротиноидов ухудшается при наличии в рационе значительного количества грубой клетчатки (34). Еще один фактор - взаимодействие между отдельными каротиноидами: считается, что ввод в рацион большого количества какого-либо каротиноида влияет на метаболизм других каротиноидов, причем может как снижать, так и повышать их всасывание. Показано, что при добавлении в рацион смесей ксантофиллов и $\beta$-каротина в примерно равных соотношениях последний ингибирует всасывание кантаксантина (35) и лютеина (36), судя по снижению их концентраций в плазме крови.

Биодоступность каротиноидов из пищевых яиц выше, чем из растительных компонентов рациона человека (37), благодаря солюбилизации в липидах яичного желтка. Так, одно обогащенное каротиноидами яйцо может обеспечить 5-10 \% от суточной потребности человека (38). По данным A. Sahoo с соавт. (39), суммарное содержание лютеина и зеаксантина в качественных пищевых яйцах составляет 0,4-0,5 мг, а яйца с содержанием порядка 2,2 мг/яйцо уже считаются дизайнерскими, то есть функциональным продуктом питания. Российские исследователи сообщали, что 
концентрация каротиноидов в яйцах от промышленных несушек, получающих стандартные рационы, составляет 20 мкг/г желтка (40).

Поскольку всасывание каротиноидов у кур также связано с метаболизмом кормовых жиров, на их доступность для птицы оказывают влияние возраст и содержание жира в рационе. Известно, что в раннем возрасте эффективность переваривания жира у кур низкая, поэтому всасывание каротиноидов в этот период онтогенеза также невелико, но с возрастом увеличивается (41). Сообщалось, что ввод дополнительных $6 \%$ жира в рацион цыплят, обогащенный лютеином, приводит к 3-кратному увеличению его отложения в тканях тела (42). В этой же работе отмечалось, что некоторые микотоксины (афлатоксины, охратоксин), а также заболевания (кокцидиоз, ньюкаслская болезнь) снижают эффективность всасывания и отложения каротиноидов в ткани тела, особенно у молодняка. Стоит отметить, что ввод в рационы несушек препаратов каротинов на фоне хронических смешанных микотоксикозов повышал сохранность птицы и снижал интенсивность клинических проявлений токсикоза (43).

Каротиноидный профиль яиц в значительной мере обусловлен рационом несушек, варьируя который можно направленно изменять и каротиноидный профиль яиц (44-46). Каротиноиды (например, кантаксантин) используются как кормовые добавки в рационах промышленных несушек для улучшения окраски желтка, однако количество и тип таких добавок могут меняться в соответствии с принятыми в стране нормами использования таких добавок и местными ценами (47). Известно, что ксантофиллы гораздо эффективнее откладываются в желток по сравнению с каротинами (48) и в значительно большей степени влияют на интенсивность окраски желтка (49). Низкая степень переноса каротиноидов с А-провитаминной активностью в желток связана с тем, что они в основном используются организмом самой несушки (50). Самые распространенные ксантофиллы в желтке яиц разных видов птиц - лютеин и зеаксантин $(51,52)$.

Эффективность пигментирования желтка яиц каротиноидами зависит от их всасывания, транспорта, экскреции, отложения в тканях и биоконверсии в организме несушек, причем на все эти факторы значительное влияние оказывают источники каротиноидов. В работе с использованием радиоактивных меток степень отложения кормовых каротиноидов в желток варьировала от 14 \% для астаксантина до 30-40 \% для кантаксантина (29). Отложение кормовых каротиноидов в желток происходит за 48 ч, хотя однородность окрашивания достигается позднее, примерно после 7-10 сут (53).

В качестве естественных источников каротиноидов в рационах кур используют кукурузу и ее производные (глютен, спиртовая барда), в том числе кукурузу, модифицированную с целью увеличения содержания различных каротиноидов (54), томаты, морковь разного каротиноидного профиля, красный перец, муку из люцерны, цветков бархатцев, календулы, богатых каротиноидами водорослей и др. (55). При этом томаты, морковь и люцерна содержат больше каротинов ( $\beta$-каротин, ликопин), чем ксантофиллов $(56,57)$. Используются также синтетические каротиноиды, для чего в последние десятилетия были разработаны препараты различного состава $(58,59)$. Следует учитывать, что не все эти источники каротиноидов пригодны для получения функциональных и/или диетических яиц. Например, специфические каротиноиды красного перца (капсантин, капсорубин), помимо антиоксидантной активности, могут проявлять аллергенные или токсические свойства (60). Использовать такие источники (даже при их низкой биодоступности для несушек) при получения яиц с заданными терапевтическими свойствами нежелательно. 
В опыте по изучению эффективности отложения кормового лютеина в желток (61) несушки получали с базовым кукурузно-соевым рационом лютеин в дозах 0, 125, 250, 375, 500, 625, 750 и 1000 г/т. При увеличении дозы кормового лютеина с 0 до 375 г/т его содержание в яйцах на 7-е сут опыта достоверно повышалось с 0,3 до 1,5 мг в расчете на 1 яйцо массой 60 г (p < 0,01). Балл интенсивности окраски желтка по цветовой шкале Рош возрастал с 6-7 до 13-14. Однако при дальнейшем росте дозы лютеина в рационе существенного увеличения его содержания в яйцах не обнаружили. Интересно отметить, что в этом опыте тот же рацион с добавкой кукурузного глютена и люцерновой муки повышал содержание лютеина в яйцах (до 2,2 мг/яйцо при дозе лютеина 500 г/т), тогда как добавка льняного семени скорее снижала этот показатель. Можно предположить, что плато насыщения желтка лютеином возникло в результате ограниченной способности печени метаболизировать кормовой лютеин и переносить его в желток в процессе вителлогенеза, а не за счет ограниченной способности лютеина к солюбилизации в липидах желтка. Источником лютеина в этом опыте служил 5 \% премикс на основе цветков бархатцев, то есть кормовой лютеин, по всей вероятности, содержал значительное количество моно- и диэфиров лютеина, которые заметно хуже усваиваются. В более позднем опыте (62) сравнивали разные дозы муки из цветков бархатцев и гидролизованного экстракта этой муки, где эфиры лютеина были подвергнуты омылению. Каждый источник скармливали в дозах 10, 20, 30 и 40 г/т в расчете на лютеин. Ни вид, ни доза препарата лютеина не оказали достоверного влияния на основные показатели качества яиц и продуктивности несушек. Отмечено улучшение показателей окраски желтка, причем достоверным оно было только при дозе 40 г/т для необработанной муки и при дозах от 20 до 40 г/т для гидролизованного экстракта. Отложение в желток общих ксантофиллов (лютеин + зеаксантин) в группах, получавших муку, а не ее гидролизованный экстракт, повышалось с 2,0 (контроль) до 4,3 мг/100 г (доза 40 г/т), а в группах, получавших экстракт, - до 5,3 мг/100 г при той же дозе кормового лютеина. Такое увеличение было связано в основном с ростом отложения лютеина, тогда как отложение зеаксантина возрастало незначительно.

В аналогичном опыте с разными дозами кантаксантина (от 0,5 до 64 г/т корма) его относительное отложение в желток составило $40 \%$, независимо от дозы в рационе, хотя абсолютное отложение вырастало при на два порядка - с 0,026 до 2,5 мг/1 яйцо (63). Отмечено также высокодостоверное $(\mathrm{p}<0,001)$ снижение индексов светлости $\left(\mathrm{L}^{*}\right)$ и желтизны $\left(\mathrm{b}^{*}\right)$ желтка и повышение индекса красноты (a*). Измерение индексов цветности желтка проводили с помощью колориметров Minolta («Konika Minolta», Япония). Эти индексы отражают светлость (L*: $0=$ черный, $100=$ белый), красноту (a*: $-100=$ зеленый, $+100=$ красный) и желтизну $\left(\mathrm{b}^{*}:-100=\right.$ синий, $+100=$ желтый) желтка. Интенсивность яйценоскости несушек оставалась сопоставимой с контролем. Недавно сообщалось, что ввод в рацион несушек кантаксантина (3 и 6 г/т) достоверно повышал не только их продуктивные показатели (интенсивность яйценоскости, массу яиц и конверсию корма), но также прочность вителлиновой мембраны в желтках свежеснесенных яиц, которая снова снижалась при хранении (64). Хотя авторы рассматривали этот показатель как характеристику инкубационных качеств яйца, он может иметь определенное значение и с точки зрения технологии переработки яиц.

В опыте чешских авторов (65) сравнивали влияние добавления в рацион несушек лютеина (250 г/т), хлореллы (12,5 кг/т) и смеси синтети- 
ческих каротиноидов Карофилл красный и Карофилл желтый («DSM Nutritional Products», Швейцария; соответственно 20 и 15 г/т) на окраску желтка, окислительную стабильность липидов желтка и продуктивность кур. Все изученные добавки достоверно увеличивали массу яиц (Карофиллы - на 2,9 \%, лютеин - на 1,6 \%, хлорелла - на 2,0\%), массу и толщину скорлупы (p < 0,001), а также снижали отношение желток/белок. При этом лютеин, в отличие от других добавок, достоверно повышал прочность скорлупы. С той же достоверностью синтетические каротиноиды и хлорелла повышали интенсивность окраски желтка яиц. Индекс красноты желтка (a*) распределялся по экспериментальным группам в следующем порядке: контроль < хлорелла < Карофиллы < лютеин; индекс желтизны $\left(b^{*}\right)$ повышался в группах, получавших хлореллу и лютеин. Лютеин и хлорелла достоверно ( $<0,001)$ увеличивали концентрацию в желтке лютеина (с 12,8 в контроле соответственно до 133,9 и 49,0 мг/кг сухого вещества) и зеаксантина (с 9,2 до 123,9 и 40,1 мг/кг сухого вещества). Все три добавки достоверно повышали окислительную стабильность липидов желтка, которую определяли по концентрации TBARS (thiobarbituric acid reactive substances - вещества, реагирующие с тиобарбитуровой кислотой) после хранения яиц в течение 28 сут при $18^{\circ} \mathrm{C}$. Добавка лютеина также достоверно увеличивала содержание в желтке витамина А и снижала количество витамина Е.

В более позднем опыте те же авторы (66) в качестве источника каротиноидов использовали экстракт цветков бархатцев (0, 150, 250 и 350 г/т корма), а также сравнили эффективность этого экстракта (при дозе 350 г/т) и смеси синтетических каротиноидов (Карофилла красного и желтого) в производственных условиях. Повышение дозы бархатцев приводило к достоверному возрастанию индексов красноты и желтизны желтка $(\mathrm{p}<0,001)$ и снижению индекса светлости ( $\mathrm{p}<0,05)$. При этом синтетические каротиноиды в промышленном опыте снижали $(\mathrm{p}<0,001)$ индекс желтизны по сравнению с контролем без добавок каротиноидов. Отложение в желток ксантофиллов с ростом дозы бархатцев в рационе увеличивалось $(\mathrm{p}<0,001)$ : по лютеину с 18,1 (контроль) до 29,8 мг/кг сухого вещества желтка (доза бархатцев 350 г/т), по зеаксантину - соответственно с 12,3 до 19,2 мг/кг. Интересно отметить, что в промышленном опыте ввод в рацион синтетических каротиноидов приводил к снижению почти на $10 \%$ (p < 0,001) содержания в желтке яиц витамина E ( $\alpha$-токоферола), тогда как в группе, получавшей бархатцы, оно не имело достоверных различий с контролем. Авторы не смогли идентифицировать натуральный или синтетический каротиноид, влияющий на отложение в желток яиц витаминов. Оптимальной дозой муки из цветков бархатцев для улучшения окраски желтка авторы считают 250 г/т, а с точки зрения экономики производства яиц 150 г/т, поскольку при дозе 250 г/т показатели продуктивности несушек несколько снижаются. К аналогичным выводам авторов привела и серия экспериментов, в которых сравнивались синтетические и натуральные источники каротиноидов (59).

В другом опыте M. Englmaierová с соавт. (67) вносили экстракт бархатцев с содержанием лютеина 21,26 и зеаксантина 9,65 мг/кг в кукурузно-пшеничный рацион в дозах $0,150,350,550,750$ и 950 г/т корма. Выявлено возрастание интенсивности яйценоскости несушек в вариантах 550 и 950 г/т и увеличение массы яиц в группах, получавших экстракт в дозах 550 и 750 г/т. Индексы красноты и желтизны желтка повышались с ростом дозы экстракта, а индекс светлости снижался. Содержание в желтке яиц лютеина и зеаксантина увеличивалось с 12,34 и 5,92 мг/кг сухого вещества 
(контроль) соответственно до 36,33 и 25,59 мг/кг (доза экстракта 950 г/т). Авторы считают, что экстракт в дозе 550 г/т может служить заменой синтетическим ксантофиллам.

B опыте F.P. Spada с соавт. (68) сравнивали влияние натурального (южноамериканский кустарник аннато) и синтетического (смесь красного и желтого Карофиллов) источников каротиноидов в рационах несушек на цвет желтка яиц, органолептические свойства свежих и хранившихся яиц (вареных и жареных), концентрацию в яйцах TBARS и эмульсионные свойства желтка. Установлено, что балл по цвету желтка свежих вареных яиц от птицы, получавшей оба источника каротиноидов, был достоверно выше, чем в контрольной группе ( $<<0,05)$; при хранении яиц это различие постепенно нивелировалось. Достоверных различий по балльной оценке запаха и текстуры желтка не наблюдали. По цвету желтка жареных яиц контроль получил более высокие баллы, что было связано с излишней, по мнению дегустаторов, краснотой желтка от кур, получавших каротиноиды. Переокисление липидов (которое оценивали по концентрации TBARS) при хранении яиц имело место во всех группах, однако в яйцах кур, получавших каротиноиды, оно прогрессировало несколько более медленно. Эмульсионные свойства желтка, которые оценивали по электрической проводимости эмульсий желтка разной концентрации, не претерпели существенных изменений при вводе обоих источников каротиноидов в рационы несушек. Авторы делают вывод, что натуральный источник может служить достаточно эффективной заменой синтетическим каротиноидам, однако для достижения необходимых органолептических и технологических свойств желтка нужно более тщательно подбирать дозировку препаратов, особенно синтетических.

Наличие эфиров каротиноидов в натуральных кормовых препаратах для несушек не только ухудшает всасывание и транспорт каротиноидов в желток, но также может оказывать влияние на жирнокислотный профиль липидов желтка. В опыте A. Altunta с соавт. (69) изучали влияние скармливания несушкам муки из цветков бархатцев (10 или 20 г/кг корма) в течение 42 сут на жирнокислотный профиль липидов желтка яиц, снесенных на последней неделе опыта. В отличие от описанного выше исследования (67), здесь масса яиц при дозе бархатцев 20 г/кг была ниже, чем в контроле. Добавка бархатцев повышала концентрацию в желтке суммы насыщенных жирных кислот и снижала содержание суммы мононенасыщенных. Авторы связывают это с тем, что в бархатцах определенная часть лютеина находится в виде эфиров с насыщенными пальмитиновой и миристиновой кислотами. В то же время для таких эфиров ранее была показана весьма незначительная степень отложения в желток - порядка $5 \%$ от дозы в рационе (53).

Обогащение рациона ксантофиллами оказывает положительное действие на состояние организма самих несушек (70). Y.-Y. Gaо с соавт. (71) изучали влияние ввода в рацион несушек с 34-й нед жизни смеси ксантофиллов (40 \% лютеина и $60 \%$ зеаксантина; 20 или 40 г/т) на показатели состояния печени и крови, характеризующие активность антиоксидантной системы (активность глутатионпероксидазы, супероксиддисмутазы и каталазы, общую антиоксидантную емкость, соотношение окисленной и восстановленной форм глутатиона, концентрацию малонового диальдегида). Установлено повышение активности антиоксидантных ферментов и снижение концентрации малонового диальдегида.

Поскольку в яйцах, особенно диетических и/или функциональных, увеличение доли насыщенных жирных кислот в липидах желтка нежела- 
тельно, оптимальными источниками ксантофиллов в рационах несушек служат синтетические препараты, где они не этерифицированы насыщенными жирными кислотами. Возможно также использование натуральных экстрактов богатых ксантофиллами растений, предварительно подвергнутых гидролизу с целью омыления эфиров ксантофиллов. Их применение может обусловливаться экономическими соображениями - доступностью и более низкой стоимостью натуральных источников по сравнению с синтетическими. В то же время при производстве «органических», экологически чистых яиц вполне возможно использовать интактные натуральные источники ксантофиллов, которые при правильном подборе состава и дозы пособны достаточно эффективно заменять синтетические каротиноиды без существенного ухудшения продуктивности несушек. К подобному выводу пришли авторы многих работ, где сравнивали синтетические и натуральные каротиноиды из наземных растений $(59,65-68)$ или морских водорослей (72).

При использовании натуральных источников ксантофиллов (особенно омыленных экстрактов) следует помнить об их нестабильности при контакте с кислородом воздуха, а также с некоторыми питательными веществами и микроэлементами (например, с железом), которые могут присутствовать в рационе несушек. Так, при хранении экстракта из цветков бархатцев содержание каротиноидов (в частности, $\beta$-каротина и лютеина), общих фенольных и общих флавоноидных соединений, а также антиоксидантная активность постепенно снижаются, причем скорость процесса зависит от температуры хранения: наиболее эффективной температурой оказалась $-20{ }^{\circ} \mathrm{C}$, а с ее ростом до $+4{ }^{\circ} \mathrm{C}$ и далее показатели снижались заметно быстрее. Авторы делают вывод, что оптимальными условиями для хранения этого продукта будет вакуумирование с замораживанием до $-20{ }^{\circ} \mathrm{C}$ (73). Поэтому после вскрытия заводской упаковки с таким препаратом его надо как можно быстрее использовать. Еще один метод стабилизации каротиноидов, облегчающий их транспорт по пищеварительному тракту к месту всасывания (дуоденум и тощая кишка) без попутного окисления, солюбилизация в растительных маслах или абсорбция на твердых частицах липидов $(74,75)$.

Таким образом, правильно подобранные источники каротиноидов, прежде всего лютеина и зеаксантина, в рационах несушек позволяют получать яйца с содержанием этих и других каротиноидов 2-3 мг/яйцо и более. Поскольку нормы потребления каротиноидов (особенно тех, которые не обладают А-провитаминной активностью) человеком пока практически отсутствуют, сложно утверждать, что обогащенные до такой степени яйца удовлетворяют количественному критерию функциональности, согласно которому продукт в количестве, соответствующем его нормальному суточному потреблению, должен обеспечивать не менее $30 \%$ рекомендованного суточного потребления целевого вещества. Однако этот процент от суточной нормы может быть заметно выше, чем 5-10 \% - порог, который приводили авторы более ранних исследований по обогащению яиц каротиноидами, с чем согласны многие авторы работ последних двух десятилетий.

ФНЦ Всероссийский научно-исследовательский и технологический институт птицеводства РАН,

141311 Россия, Московская обл., г. Сергиев Посад, ул. Птицеградская, 10,

e-mail: alexk@vnitip.ru $\bowtie$, dp.vniipp@mail.ru, 89267796966@yandex.ru
Поступила в редакцию 6 июня 2019 года 


\section{OF THE CAROTENOIDS}

(review)

\section{A.Sh. Kavtarashvili, I.L. Stefanova, V.S. Svitkin}

Federal Scientific Center All-Russian Research and Technological Poultry Institute RAS, 10, ul. Ptitsegradskaya, Sergiev Posad, Moscow Province, 141311 Russia, e-mail alexk@vnitip.ru ( $₫$ corresponding author), dp.vniipp@mail.ru, 89267796966@yandex.ru

ORCID:

Kavtarashvili A.Sh. orcid.org/0000-0001-9108-1632Ｓ Svitkin V.S. orcid.org/0000-0002-4161-0986

Stefanova I.L. orcid.org/0000-0002-4394-5149

The authors declare no conflict of interests

Functional egg production. I. The role of $\omega-3$ polyunsaturated fatty acids (review). Agricultural Biology, 2017, vol. 52, No 2: 349-366 (doi: 10.15389/agrobiology.2017.2.349rus, doi: 10.15389/agrobiology.2017.2.349eng).

Functional egg production. II. The roles of selenium, zinc, and iodine (review). Agricultural Biology, 2017, vol. 52, No 4: 700-715 (doi: 10.15389/agrobiology.2017.4.700rus, doi: 10.15389/agrobiology.2017.4.700eng).

Acknowledgements:

Supported financially by Russian Science Foundation, grant No 16-16-04047

Received June 6, 2019

doi: 10.15389/agrobiology.2019.4.681eng

\section{Abstract}

Recent growth of public awareness on the role of carotenoids (especially xanthophylls) in the prophylaxis and dietotherapy of certain oncologic, cardiovascular, and ocular diseases in human related to antioxidative and immunomodulating properties (E. Bakan et al., 2014) made these substances used earlier for the improvement of egg yolk color (and, as a consequence, attractibility of the eggs for consumers) valuable target substances in the production of dietetic, designer, and functional eggs (V.P. Singh et al., 2012). High bioavailability of carotenoids from table eggs due to the solubilization in yolk lipids makes the eggs a suitable source of carotenoids for the enrichment of human diet (H.-Y. Chung et al., 2004). In the study presented different aspects of practical production of functional eggs enriched with carotenoids are reviewed: the sources of carotenoids in the diets for laying hens and their comparative efficacy; metabolism of carotenoids in hens and its relation to the metabolism of lipids; the effects of different xanthophyll sources on health and productivity in hens, egg quality, the intensity of yolk coloration, concentrations of xanthophylls in yolk. The main advantage of synthetic preparations of carotenoids is their high availability for the layers (M. Marounek et al., 2016); however, due to their expensiveness these sources can be economically unprofitable in the production of enriched eggs. Natural sources of basic yolk carotenoids, lutein and zeaxanthin (S.M. Vostrikova et al., 2011), e.g. marigold (Tagetes spp.), frequently contain substantial part of these xanthophylls as ethers with fatty acids; the availability of these forms for layers is significantly lower in compare to the saponified forms (K. Lokaewmanee et al., 2011). These sources can be preliminary saponified to release the etherified xanthophylls: it will improve the availability of the latter for layers by 40-60\%, the transfer of these substances to egg yolks (H. Hencken, 1992), and prevent the resulting fatty acid profiles of eggs from the shift to higher percentage of saturated fatty acids (A. Altunta et al., 2014). The disadvantage of this approach is related to low stability of saponified preparations during the storage; researchers recommend these preparations to be stored frozen and to be used as soon as possible after the unpacking. Different effects of the sources of xanthophylls on the productive performance in layers (primarily the intensity of lay, egg weight and morphology) were reported: certain authors reported the significant improvements of these productivity parameters while other authors found these parameters to remain at the level of control treatments or be slightly lower. The majority of studied sources providing xanthophylls in the forms available for layers substantially and significantly improves the parameters of yolk coloration intensity (decreases index of lightness $\mathrm{L}^{*}$ and increases indices of yellowness $\mathrm{b}^{*}$ and redness $\mathrm{a}^{*}$ ) and concentrations of lutein and zeaxanthin in yolk. Reasonable choice of sources and doses can result in eggs enriched with xanthophylls to the extent where the eggs could be considered functional carotenoid sources for human (A. Sahoo et al., 2014), though no normal consumption rates for the xanthophylls irrespective to specific diseases were so far developed (E. Toti et al., 2018).

Keywords: functional eggs, carotenoids, lutein, zeaxanthin, layer diet, dietary carotenoid sources, egg yolk quality.

\section{R E F E R E N C ES}

1. Kavtarashvili A.Sh., Stefanova I.L., Svitkin V.S., Novotorov E.N. Functional egg production. I. the role of $\omega-3$ polyunsaturated fatty acids (review). Sel'skokhozyaistvennaya biologiya [Agricultural Biology], 2017, 52(2): 349-366 (doi: 10.15389/agrobiology.2017.2.349eng).

2. Kavtarashvili A.Sh., Stefanova I.L., Svitkin V.S., Novotorov E.N. Finctional egg production. II. The roles of selenium, zinc, and iodine (review). Sel'skokhozyaistvennaya biologiya [Agricultural 
Biology], 2017, 52(4): 700-715 (doi: 10.15389/agrobiology.2017.4.70eng).

3. Kavtarashvili A.Sh., Kodentsova V.M., Mazo V.K., Risnik D.V., Stefanova I.L. Biofortification of hen eggs: vitamins and carotenoids (review). Sel'skokhozyaistvennaya biologiya [Agricultural Biology], 2017, 52(6): 1094-1104 (doi: 10.15389/agrobiology.2017.6.1094eng).

4. Wagner K.H., Elmadfa I. Biological relevance of terpenoids. Overview focusing on mono-, diand tetraterpenes. Ann. Nutr. Metab., 2003, 47: 95-106 (doi: 10.1159/000070030).

5. Oliver J., Palou A. Chromatographic determination of carotenoids in foods. Journal of Chromatography A, 2000, 881(1-2): 543-555 (doi: 10.1016/S0021-9673(00)00329-0).

6. Amorim-Carrilho K.T., Cepeda A., Fente C., Regal P. Review of methods for analysis of carotenoids. TrAC Trends in Analytical Chemistry, 2014, 56: 49-73 (doi: 10.1016/j.trac.2013.12.011).

7. Sajilata M.G., Singhal R.S., Kamat M.Y. The carotenoid pigment zeaxanthin - a review. Comprehensive Reviews in Food Science and Food Safety, 2008, 7(1): 29-49 (doi: 10.1111/j.15414337.2007.00028.x).

8. Olson J.A., Krinsky N.I. Introduction: the colorful fascinating world of the carotenoids: important physiologic modulators. FASEB J., 1995, 9(15): 1547-1550 (doi: 10.1096/fasebj.9.15.8529833).

9. Hurst W.J. Methods of analysis for functional foods and nutraceuticals. $2^{\text {nd }}$ Ed. CRC Press, Boca Raton, London-NY, 2008.

10. Britton G. Structure and properties of carotenoids in relation to function. FASEB J., 1995, 9(15): 1551-1558 (doi: 10.1096/fasebj.9.15.8529834).

11. Merhan O., Özcan A., Atakişi E., Öğün M., Kükürt A. The effect of $\beta$-carotene on acute phase response in diethylnitrosamine given rabbits. Kafkas Univ. Vet. Fak. Derg., 2016, 22(4): 533-537 (doi: 10.9775/kvfd.2016.14995).

12. Gammone M.A., Riccioni G., D’Orazio N. Marine carotenoids against oxidative stress: effects on human health. Marines Drugs, 2015, 13(10): 6226-6246 (doi: 10.3390/md13106226).

13. Krinsky N.I., Johnson E.J. Carotenoid actions and their relation to health and disease. Mol. Aspects Med., 2005, 26(6): 459-516 (doi: 10.1016/j.mam.2005.10.001).

14. García E.F., Lérida I.C., Galán M.J., Fernández J.G., Gálvez A.P., Méndez D.H. Carotenoids bioavailability from foods: from plant pigments to efficient biological activities. Food Research International, 2012, 46(2): 438-450 (doi: 10.1016/j.foodres.2011.06.007).

15. Bakan E., Akbulut Z.T., Inanç A.L. Carotenoids in foods and their effects on human health. Acad. Food J., 2014, 12(2): 61-68.

16. Tapiero H., Townsend D.M., Tew K.D. The role of carotenoids in the prevention of human pathologies. Biomedicine \& Pharmacotherapy, 2004, 58(2): 100-110 (doi: 10.1016/j.biopha.2003.12.006).

17. Tavani A., Gallus S., Neqri E., Parpinel M., La Vecchia C. Dietary intake of carotenoids and retinol and the risk of myocardial infarction in Italy. Free Radical Research, 2006, 40(6): 659664 (doi: 10.1080/10715760600615649).

18. Ito Y., Kurata M., Suzuki K., Hamajima N., Hishida H., Aoki K. Cardiovascular disease mortality and serum carotenoid levels: a Japanese population-based follow-up study. J. Epidemiol., 2006, 16(4): 154-160.

19. Buijsse B., Feskens E.J., Schlettwein-Gsell D., Ferry M., Kok F.J., Kromhout D., de Groot L.C. Plasma carotene and alpha-tocopherol in relation to 10-y all-cause and causespecific mortality in European elderly: the survey in Europe on nutrition and the elderly, a concerted action (SENECA). The American Journal of Clinical Nutrition, 2005, 82(4): 879-886 (doi: 10.1093/ajcn/82.4.879).

20. Kabagambe E.K., Furtado J., Baylin A., Campos H. Some dietary and adipose tissue carotenoids are associated with the risk of nonfatal acute myocardial infarction in Costa Rica. The Journal of Nutrition, 2005, 135(7): 1763-1769 (doi: 10.1093/jn/135.7.1763).

21. Saksonova E.O. Rossiiskii meditsinskii zhurnal, 2005, 13(2): 124-129 (in Russ.).

22. Kijlstra A., Tian Y., Kelly E.R., Berendschot T.T. Lutein: more than just a filter for blue light. Progress in Retinal and Eye Research, 2012, 31(4): 303-315 (doi: 10.1016/j.preteyeres.2012.03.002).

23. Ham W.T., Mueller H.A., Ruffolo J.J., Millen J.E., Cleary S.F., Guerry R.K., Guerry D. Basic mechanisms underlying the production of photochemical lesions in the mammalian retina. Current Eye Research, 1984, 3(1): 165-174 (doi: 10.3109/02713688408997198).

24. Khachik F., Bernstein P.S., Garland D.L. Identification of lutein and zeaxanthin oxidation products in human and monkey retinas. Investigative Ophthalmology \& Visual Science, 1997, 38(9): 1802-1811.

25. Chitchumroonchokchai C., Bomser J.A., Glamm J.E., Failla M.L. Xanthophylls and alphatocopherol decrease UVB-induced lipid peroxidation and stress signaling in human lens epithelial cells. The Journal of Nutrition, 2004, 134(12): 3225-3232 (doi: 10.1093/jn/134.12.3225).

26. Lessin W.J., Catigani G.I., Schwartz S.J. Quantification of cis-trans isomers of provitamin A carotenoids in fresh and processed fruits and vegetables. J. Agric. Food Chem., 1997, 45(10): 3728-3732 (doi: 10.1021/jf960803z).

27. Southon S., Faulks R. Carotenoids in food: bioavailability and functional benefits. In: Phytochemical functional foods. I. Johnson, G. Williamson (eds.). CRC Press, Boca Raton, BostonNY-Washington, DC, 2003: 107-127.

28. Olson J.A. Absorption, transport, and metabolism of carotenoids in humans. Pure and Applied 
Chemistry, 1994, 66(5): 1011-1016 (doi: 10.1351/pac199466051011).

29. Hencken H. Chemical and physiological behavior of feed carotenoids and their effects on pigmentation. Poultry Science, 1992, 71(4): 711-717 (doi: 10.3382/ps.0710711).

30. Schaeffer J.L., Tyczkowski J.K., Parkhurst C.R., Hamilton P.B. Carotenoid composition of serum and egg yolks of hens fed diets varying in carotenoid composition. Poultry Science, 1988, 67(4): 608-614 (doi: 10.3382/ps.0670608).

31. Matsufuji H., Nakamura H., Chino M., Takeda M. Antioxidant activity of capsanthin and the fatty acid esters in paprika (Capsicum annuum). J. Agric. Food Chem., 1998, 46(9): 3468-3472 (doi: 10.1021/jf980200i).

32. van het Hof K.H., West C.E., Weststrate J.A., Hautvast J.G. Dietary factors that affect the bioavailability of carotenoids. The Journal of Nutrition, 2000, 130(3): 503-506 (doi: 10.1093/jn/130.3.503).

33. de Pee S., West C.E., Permaesih D., Muhilal S.M., Hautvast J. Orange fruit is more effective than are dark-green, leafy vegetables in increasing serum concentrations of retinol and $\beta$ carotene in schoolchildren in Indonesia. The American Journal of Clinical Nutrition, 1998, 68(5): 1058-1067 (doi: 10.1093/ajcn/68.5.1058).

34. Rock C.L. Carotenoids: biology and treatment. Pharmacology \& Therapeutics, 1997, 75: 185-197 (doi: 10.1016/S0163-7258(97)00054-5).

35. Paetau I., Chen H., Goh N., White W.S. Interactions in the postprandial appearance of $\beta$ carotene and canthaxanthin in plasma triacylglycerol-rich lipoproteins in humans. The American Journal of Clinical Nutrition, 1997, 66(5): 1133-1143 (doi: 10.1093/ajcn/66.5.1133).

36. Kostic D., White W.S., Olson J.A. Intestinal absorption, serum clearance, and interactions between lutein and $\beta$-carotene when administered to human adults in separate or combined oral doses. The American Journal of Clinical Nutrition, 1995, 62(3): 604-610 (doi: 10.1093/ajen/62.3.604).

37. Chung H.-Y., Rasmussen H.M., Johnson E.J. Lutein bioavailability is higher from luteinenriched eggs than from supplements and spinach in men. The Journal of Nutrition, 2004, 134(8): 1887-1893 (doi: 10.1093/jn/134.8.1887).

38. Handelman G.J., Nightingale Z.D., Lichtenstein A.H., Schaefer E.J., Blumberg J.B. Lutein and zeaxanthin concentrations in plasma after dietary supplementation with egg yolk. The American Journal of Clinical Nutrition, 1999, 70(2): 247-251 (doi: 10.1093/ajcn.70.2.247).

39. Sahoo A., Jena B. Designer egg and meat through nutrient manipulations. Journal of Poultry Science and Technology, 2014, 2(3): 38-47.

40. Deineka L.A., Shaposhnikov A.A., Vostrikova S.M., Deineka V.I. Nauchnye vedomosti Belgorodskogo gosudarstvennogo universiteta. Seriya Estestvennye nauki, 2007, 5(36), vyp. 5: 133-138 (in Russ.).

41. Tancharoenrat P., Ravindran V., Zaefarian F., Ravindran G. Influence of age on the apparent metabolisable energy and total tract apparent fat digestibility of different fat sources for broiler chickens. Animal Feed Science and Technology, 2013, 186(3-4): 186-192 (doi: 10.1016/j.anifeedsci.2013.10.013).

42. Hamilton P.B. The use of high-performance liquid chromatography for studying pigmentation. Poultry Science, 1992, 71(4): 718-724 (doi: 10.3382/ps.0710718).

43. Kuz'minova E.V. Farmakologiya i primenenie karotinoidov v veterinarii i zhivotnovodstve. Avtoreferat doktorskoi dissertatsii [Pharmacology of carotenoids and their use in veterinary medicine and animal husbandry. DSc Thesis]. Krasnodar, 2007 (in Russ.).

44. Karadas F., Grammenidis E., Surai P.F., Acamovic T., Sparks N.H. Effects of carotenoids from lucerne, marigold and tomato on egg yolk pigmentation and carotenoid composition. British Poultry Science, 2006, 47(5): 561-566 (doi: 10.1080/00071660600962976).

45. Fisinin V.I., Shtele A.L. Ptitsa i ptitseprodukty, 2008, 5: 58-60 (in Russ.).

46. Fisinin V.I., Shtele A.L. Ptitsa i ptitseprodukty, 2008, 6: 50-52 (in Russ.).

47. Breithaupt D.E. Modern application of xanthophylls in animal feeding - a review. Trends in Food Science \& Technology, 2007, 18(10): 501-506 (doi: 10.1016/j.tifs.2007.04.009).

48. Singh V.P., Pathak V., Akhilesh K.V. Modified or enriched eggs: a smart approach in egg industry: a review. American Journal of Food Technology, 2012, 7(5): 266-277 (doi: 10.3923/ajft.2012.266.277).

49. Loetscher Y., Kreuzer M., Messikommer R.E. Utility of nettle (Urtica dioica) in layer diets as a natural yellow colorant for egg yolk. Animal Feed Science and Technology, 2013, 186(3-4): 158168 (doi: 10.1016/j.anifeedsci.2013.10.006).

50. Surai P.F., Speake B.K., Sparks N.H.C. Carotenoids in avian nutrition and embryonic development. 1. Absorption, availability and levels in plasma and egg yolk. The Journal of Poultry Science, 2001, 38(1): 1-27 (doi: 10.2141/jpsa.38.1).

51. Vladimirov V.L., Shaposhnikov A.A., Deineka D.V., Vostrikova S.M., Deineka V.I. Doklady RASKHN, 2005, 6: 46-48 (in Russ.).

52. Vostrikova S.M., Tret'yakov M.Yu., Deineka V.I., Deineka L.A., Shaposhnikov A.A. Nauchnye vedomosti Belgorodskogo gosudarstvennogo universiteta. Seriya Estestvennye nauki, 2011, 9(104), vyp. 15/2: 221-227 (in Russ.).

53. Nys Y. Dietary carotenoids and egg yolk coloration - a review. Archiv fur Geflugelkunde, 2000, 64(2): 45-54.

54. Moreno J.A., Díaz-Gómez J., Nogareda C., Angulo E., Sandmann G., Portero-Otin M., Serra- 
no J.C.E., Twyman R.M., Capell T., Zhu Ch., Christou P. The distribution of carotenoids in hens fed on biofortified maize is influenced by feed composition, absorption, resource allocation and storage. Sci. Rep., 2016, 6: 35346 (doi: 10.1038/srep35346).

55. Abdel-Aal E.S.M., Akhtar H., Zaheer Kh., Ali R. Dietary sources of lutein and zeaxanthin carotenoids and their role in eye health. Nutrients, 2013, 5(4): 1169-1685 (doi: 10.3390/nu5041169).

56. Laudadio V., Ceci E., Lastella N.M.B., Introna M., Tufarelli V. Low-fiber alfalfa (Medicago sativa L.) meal in the laying hen diet: effects on productive traits and egg quality. Poultry Science, 2014, 93(7): 1868-1874 (doi: 10.3382/ps.2013-03831).

57. Alagawany M., Farag M.R., Dhama K., Patra A. Nutritional significance and health benefits of designer eggs. World's Poultry Science Journal, 2018, 74(2): 317-330 (doi: 10.1017/S0043933918000041).

58. Egorov I.A., Lukashenko V.S., Borisova T.V., Dyadichkina L.F., Golovachev D.E., Kalashnikov A.I., Khamidullin T.N., Semenova E.A., Semenova E.A., Kuznetsov A.S. Ispol'zovanie promyshlennykh preparatov karotinoidov firmy BASF v kormlenii ptitsy: metodicheskie rekomendatsii /Pod redaktsiei V.I. Fisinina, Sh.A. Imangulova [The use of BASF carotenoids in poultry feeding: guidelines. V.I. Fisinin, Sh.A. Imangulov (eds.)]. Sergiev Posad, 2002 (in Russ.).

59. Marounek M., Skřivan M., Englmaierová M. Comparison of natural and synthetic carotenoids: Effection yolk colour and oxidative stability of yolk lipids. International Journal of Advances in Science Engineering and Technology, 2016, 5: 53-55.

60. EFSA (European Food Safety Authority). Scientific opinion on the re-evaluation of paprika extract (E 160c) as a food additive. EFSA J., 2015, 13(12): 4320 (doi: 10.2903/j.efsa.2015.4320).

61. Leeson S., Caston L. Enrichment of eggs with lutein. Poultry Science, 2004, 83(10): 1709-1712 (doi: 10.1093/ps/83.10.1709).

62. Lokaewmanee K., Yamauchi K., Komori Ts., Saito K. Enhancement of yolk color in raw and boiled egg yolk with lutein from marigold flower meal and marigold flower extract. The Journal of Poultry Science, 2011, 48(1): 25-32 (doi: 10.2141/jpsa.010059).

63. Grashorn M., Steinberg W. Deposition rates of canthaxanthin in egg yolks. Archiv fur Geflugelkunde, 2002, 66(6): 258-262.

64. Damaziak K., Marzec A., Riedel J., Szeliga J., Koczywąs E., Cisneros F., Michalczuk M., Lukasiewicz M., Gozdowski D., Siennicka A., Kowalska H., Niemiec J., Lenart A. Effect of dietary canthaxanthin and iodine on the production performance and egg quality of laying hens. Poultry Science, 2018, 97(11): 4008-4019 (doi: 10.3382/ps/pey264).

65. Englmaierová M., Skřivan M., Bubancová I. A comparison of lutein, spray-dried Chlorella, and synthetic carotenoids effects on yolk colour, oxidative stability, and reproductive performance of laying hens. Czech J. Anim. Sci., 2013, 58(9): 412-419 (doi: 10.17221/6941-CJAS).

66. Skřivan M., Englmaierová M., Skřivanová E., Bubancová I. Increase in lutein and zeaxanthin content in the eggs of hens fed marigold flower extract. Czech J. Anim. Sci., 2015, 60(3): 89-96 (doi: 10.17221/8073-CJAS).

67. Skřivan M., Marounek M., Englmaierová M., Skřivanová E. Effect of increasing doses of marigold (Tagetes erecta) flower extract on eggs carotenoids content, colour and oxidative stability. $J$. Anim. Feed Sci., 2015, 25(1): 58-64 (doi: 10.22358/jafs/65588/2016).

68. Spada F.P., Selani M.M., Coelho A.A.D., Savino V.J.M., Rodella A.A., Souza M.C., Fischer F.S., Lemes D.E.A., Canniatti-Brazaca S.G. Influence of natural and synthetic carotenoids on the color of egg yolk. Scientia Agricola, 2016, 73(3): 234-242 (doi: 10.1590/0103-9016-2014-0337).

69. Altunta A., Aydin R. Fatty acid composition of egg yolk from chickens fed a diet including marigold (Tagetes erecta L.). Journal of Lipids, 2014, Article ID 564851 (doi: 10.1155/2014/564851).

70. Guseva T.S. Biokhimicheskii status kur-nesushek $i$ kachestvo yaits pri ispol'zovanii $v$ ikh ratsione karotinoidov rastitel'nogo i mikrobiologicheskogo sinteza. Kandidatskaya dissertatsiya [Biochemical status and egg quality of laying hens in using dietary carotenoids of plant and microbial origin. PhD Thesis]. Belgorod, 2008 (in Russ.).

71. Gao Y.-Y., Xie Q.-M., Ma J.Y., Zhang X.-B., Zhu J.-M., Shu D.-M., Sun B.-L., Jin L., Bi Y.-Z. Supplementation of xanthophylls increased antioxidant capacity and decreased lipid peroxidation in hens and chicks. British Journal of Nutrition, 2013, 109: 977-983 (doi: 10.1017/S0007114512002784).

72. Zahroojian N., Moravej H., Shivazad M. Comparison of marine algae (Spirulina platensis) and synthetic pigment in enhancing egg yolk colour of laying hens. British Poultry Science, 2011, 52(5): 584-588 (doi: 10.1080/00071668.2011.610779).

73. Akshaya H.R., Banyal N., Singh K.P., Saha S., Panwar S., Bharadwaj C. Standardization of storage conditions of marigold (Tagetes sp.) petal extract for retention of carotenoid pigments and their antioxidant activities. Indian Journal of Agricultural Sciences, 2017, 87(6): 765-775.

74. Boon C.S., McClements D.J., Weiss J., Decker E.A. Factors influencing the chemical stability of carotenoids in foods. Critical Reviews in Food Science and Nutrition, 2010, 50(6): 515-532 (doi: 10.1080/10408390802565889).

75. Toti E., Chen C.-Y. O., Maura Palmery M., Valencia D.V., Peluso I. Non-provitamin A and provitamin A carotenoids as immunomodulators: recommended dietary allowance, therapeutic index, or personalized nutrition? Oxid. Med. Cell Longev., 2018; Article ID 4637861 (doi: $10.1155 / 2018 / 4637861)$. 